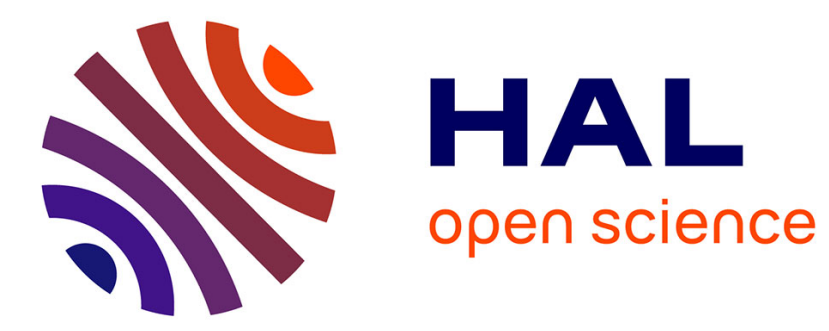

\title{
Re-figuring Gilbert the Drone
}

Mads Bødker, Stefan Olavi Olofsson, Torkil Clemmensen

\section{To cite this version:}

Mads Bødker, Stefan Olavi Olofsson, Torkil Clemmensen. Re-figuring Gilbert the Drone. Working Conference on Information Systems and Organizations (IS\&O), Dec 2018, San Francisco, CA, United States. pp.127-139, 10.1007/978-3-030-04091-8_10 . hal-02083595

\section{HAL Id: hal-02083595 \\ https://hal.inria.fr/hal-02083595}

Submitted on 29 Mar 2019

HAL is a multi-disciplinary open access archive for the deposit and dissemination of scientific research documents, whether they are published or not. The documents may come from teaching and research institutions in France or abroad, or from public or private research centers.
L'archive ouverte pluridisciplinaire HAL, est destinée au dépôt et à la diffusion de documents scientifiques de niveau recherche, publiés ou non, émanant des établissements d'enseignement et de recherche français ou étrangers, des laboratoires publics ou privés. 


\title{
Re-figuring Gilbert the Drone
}

\author{
Mads Bødker ${ }^{[1]}$ Stefan Olavi Olofsson ${ }^{[2]}$ Torkil Clemmensen $^{[1]}$ \\ ${ }^{1}$ Copenhagen Business School, 2000 Frederiksberg, Denmark \\ ${ }^{2}$ Independent Researcher \\ mb.digi@cbs.dk
}

\begin{abstract}
In the paper we offer a story of re-figuring a consumer drone as a way of "living with monsters". If drones are "monstrous", what potentials might lie in re-framing them as more benign, civic, or even perhaps enchanted? Based on a field study of work at a makerspace, we present re-figuring as a process of reflecting, interacting and imagining the function of a drone, using gradually developing intuitions as well as an emergent felt 'sense' of the drone in practice. Using an analytic trajectory broadly based on philosophies of affect, we suggest how felt relations to technology can potentially become further involved in a critical move towards re-figuring "monstrous" technologies.
\end{abstract}

Keywords: drones, re-figuring, design

\section{Introduction}

This paper explores the case of working with a drone as a companion technology in ways that deliberately attempt to re-figure the drone as a technology. The rate of privately owned drones is predicted to increase extensively over the coming years. An estimate from the US Federal Aviation Agency estimates that the number of privately owned hobbyist drones will exceed 3.5 million in 2021 [1]. Drones are here to stay, but what form will they take physically as well as discursively, affectively? How will we talk about them, what roles will they play, and how will we live with them? These are some of the broader questions that this paper pursues.

Drones may invoke images of war and violence, as well as connotations of privacy invasion and surveillance. Drones, as a phenomenon, have become at least partially anchored in representations that accentuate the more menacing properties of the technology [2]. Some analysts emphasize how drones are involved in a larger 'surveillant assemblage' [3] and how "the figure of the drone is useful because it offers a highly visible and controversial example of the deployment of networked surveillance and quasi-automated response and suggests the ways in which the implementation of drone logic across disparate spheres of social practice partakes of the military-inflected rationalization of everyday life" [4: 21]. According to e.g. [5], when users are confronted with actual drones, negative figurations seem to prevail. Long-standing concerns over privacy are compounded with "evidence of negative perceptions around drones such as fear of damage or injury and unwillingness to disclose personal information under drone surveillance" [5: 6765]. 
The figure of drones is not only constituted discursively and in terms of "meaning", i.e. in terms of the narratives or signification, but also affectively within a particular historical present. Droning is an invisibly-menacing technological modus that is discursively constructed in language, but at the same time an incarnate, felt and affective ubiquitous presence: we cannot necessarily see the drones, but they are there, they may hover! It can create knots in our stomach when we think about the eye-in-the-sky, we may flinch involuntarily at the idea of small, autonomously flying vehicles.

We argue that drones are 'monstrous', but not necessarily violently so. Monsters emerge as hybrid assemblages of humans and technology in technologically affluent societies. Monsters can be felt as threatening but also invoke reveries, potentials and promises. They inhabit the liminal spaces between humans and things; a space where convenient and conventional classifications into essential categories such as "the human" and "technology" seem to collapse. Drones can be aggressive and violent in one figuration, invoking images and feelings of terror, surveillance and so on. They can also be benign, helpful, yet still somewhat "foreign bodies", mysterious and somewhat speculative. They fly, they travel, bafflingly, through the air, nimble floating creatures as well as rather mundane and grey plasticky things when they run out of battery. They are transgressive objects that have not yet become normalized within specific discursive boundaries. They have yet to become stable technological objects with circumscribed, discrete connotations. Perhaps because they were originally intimately linked to military applications, it is difficult to appreciate fully those (possible) benign figures as they are currently too unstable, explorative, and emergent.

As a response to the question of "living with monsters", our paper details the early parts of a process of working with a drone in a maker lab. In the paper, we employ ideas from affect theory (e.g. [6]) and the notions of enchantment and evocative objects (e.g. [7-9] as ways of conceptualizing the processes of re-figuring a drone.

\section{Theories}

Our paper relies on an overall orientation towards concepts from the so-called affective turn in the humanities and the social sciences [6]. We use these theoretical approaches to emphasize how a technology is experienced or felt as e.g. a threat or a promise, not only as semiotics, an icon, index or a symbol of "something else", but also something that 'flies below the radar' of signification: a mood, a felt sense of things, something in excess of meaning. In affect theories, sense and sensation seem to unfold in an embodied and sociomaterially entangled organism [10] before conventional notions of decoding or 'cognition' kicks in. This is a complex collection of literatures that we will not in any way present in much detail, but they tend to share a concern for what goes on "beyond, below and past discourse" [11: 350], shunning conventional language and conventional meaning. It reverses the concepts of "standard modernist blueprints" that "suggest the existence of a self-governing, psychological subject - a subject essentially assumed to be autonomous and informationally closed to the outside world - affect theories suggest instead that humans can be understood as intimately (and messily, 
unpredictably) entangled in continuous vital and felt exchanges with the world” [12: 179].

Affect as a form of excess beyond conventional meaning allow us to talk about the felt and embodied relations to technology [13]. It suggests potentials for research that explores the felt, messy, and ephemeral/fleeting senses of things that might appear in interacting with them. Affect theory also points to somewhat neglected aspects of sociomaterial theorizing. Affect is not posited as something internal to the subject. Unlike the idea of emotions, which provides us with a clear structure of an inside (the feeling) and an outside (the expression), as well as with a form of causality, affects are neither fully 'inside' the subject, nor fully outside in the environment or the objects [6]. In that way, affects are perhaps an expression of what we might term the "sociomateriality of feeling". Material things are entangled in how we feel as well as in what we do. As Bødker \& Jensen suggest; "the socio-materiality of practices can usefully be complemented by a notion of affective entanglements; i.e., the embodied materiality of feeling. In this way, moods, feelings, and felt embodiment (similarly to practices) are relational performances of people and machines” [14: 3005]. In particular, we find that Jane Bennett's notions of enchantment and vibrant materiality $[7,8]$ provide us with new ways of thinking about affective relations to things. Below, we suggest how these perspectives might play a role in design.

\subsection{Design and affect}

The "generative valence" of affect has been noted by [15]. They suggest that affect is "the pre-conscious, pre-intentional, pre-verbal processes that occur between bodies" [15: 82] and they indicate how affective properties and materialities within a design practice are "a found (and an always reconstituting) force, one that stands out as a littleutilised, yet always pervasive, generative agent." [15: 90]. Things exert a force and afford an intensity, they attract and collect words, feelings or agendas. Places, situations, events and shared 'structures of feeling' [16 $128 \mathrm{ff}$.] or 'atmospheres' [17] (en)force or modulate behaviors, ideas or moods. However, these qualities of a tend to go unnoticed by conventional social science vocabularies and more readily acceptable notions such as structure or agency, hierarchies, management, or process adherence.

With these initial concerns about the process and object of design, our approach trails a number of critical and speculative design approaches. Most notably Dunne and Raby's notion of Critical Design [18-21] that has been described as "a form of research aimed at leveraging designs to make consumers more critical about their everyday lives, and in particular how their lives are mediated by assumptions, values, ideologies, and behavioral norms inscribed in designs" [22: 3298]. Critical design "holds the design profession to account for its complicity with capitalist ideology and alienation. It names some design values of global capitalism - conformity, obedience, easy pleasure, and corporate identity, among others. It challenges designers and consumers alike to envision - and to demand - design products that reflect a more challenging view of human needs and experience" [22: 3298).

We understand the drone as a figure that has not yet been exhausted, where a number of potential figures lie beyond the image of drones as tools for policing or violence and 
towards even more benign and likable accomplices in everyday life. What happens if a drone is conceptualized as a companion technology or as a benign escort, maybe not unlike countless "science fiction" versions of autonomous machines, robots or drones that have personalities, alliances, histories, feelings, and expressive dispositions?

Such figures, we argue, can be explored affectively, as "[it] is through attention to these affective materialities that we can design for affect" [15: 90]. The affective dynamics of a design process can be a part of the fabric that engenders critical design and speculation based on affective and indeed fleeting imaginations or gut feelings can be a designerly means to engage critically with the inherent openness of objects and the unpredictability and hence malleability of material- and social futures. We propose that feelings and affective dispositions matter in (speculative) design processes and we propose some opportunities and motivations for extending the affect philosophical lines of inquiry in design- and information systems research.

\section{$3 \quad$ Method}

As the initial inspiration for our observations and subsequent reflections we relied on Pink, Akama \& Sumartojo's argument that "uncertainty [can be] re-figured as a methodological device rather than as just an object of study [...] uncertainty can be understood as a generative technology" [23: 43, emphasis in original]. In our case, one of the authors happened to work in a collective of people with an interest in building, trying out and hacking things, in an effort to re-think and re-know "drones" as an idea and as a thing.

The design process with the drone was not initiated or contextualized as a purposeful generation of a specific solution, but was driven along by what initially felt like a curiosity and an intense shared interest in the design group. The primary data collection by the second author was followed up by discussion and subsequent data collection and explorations by the $1^{\text {st }}$ and $3^{\text {rd }}$ author, who collaborated on the framing of the paper.

The intention in the paper is not to attempt a final interpretation of our data, but rather to begin training a theoretical lens on our fieldwork. What is presented are shorter stories and situations that influenced the direction and ongoing reconceptualization of the drone and the way it emerged as a particular object to us as researchers. The narratives below are created collaboratively by all three authors around the details provided by the second author. Primary data has been collected over the course of approximately 4 months, in the fall of 2016, primarily in a maker lab in Malmö, Sweden. The writeup here takes the form of a series of vignettes [24] that account for some of the processes and events during the stay. The material for writing up the vignettes is primarily notes and reconstructions at later stages of the $2^{\text {nd }}$ author's work in the maker lab as well as emails, digital communications, and shared reflections between all three authors. Also, field trials and structured observations of drones and drone flying provided all authors a sense of what flying a drone feels like, and how people feel about being in the vicinity of a 'live' drone.

In late 2016, the first author began working in a local community maker lab in Malmö in Southern Sweden. It included visiting the space located at a defunct factory 
site multiple times per week, at different times of day. The researcher spent time with a small group of community members as well as guests in the space and other people who became enrolled in the various networks and projects around the facility. Over some time, the people in the space became informants for research, even if the site was originally not intentionally chosen as a research site, nor were the colleagues intended as informants. As colleague-informants, the designers in the maker lab were continuously commenting, sharing knowledge, adding suggestions and ideas in daily 'water cooler' conversations as well as in more structured reflections and idea generation processes. The $1^{\text {st }}$ and $3^{\text {rd }}$ author further provided structured observations and reflections on drone use, design, flying and the sense of operating a drone remotely. These observations and the sense of what drones are, how they are experienced, figured and felt are interspersed within the overall narrative of the drone that came to be known as Gilbert.

\section{$4 \quad$ Life of a Drone}

\subsection{Arrival}

So, a drone had been procured for our maker lab in order to complement the collection of hack-able gadgets and devices available to the maker community. Initially, the intention of my work at the maker space was simple: figure out what to do with the drone. It was all a bit confusing - here's an expensive drone, what can we do with it? I had no idea.

"On one evening when I brought the drone home with me (pics attached) my wife was visiting Sweden. We began discussing drones, and we talked about how DJI is a Chinese company, and that DJI Phantom has a different name in China. In China, the DJI Phantom drone is called DJI 'elf/fairy', in Chinese specifically jingling 精灵 and based on a Chinese version of Wikipedia on Baidu the drone was meant to help nontech savvy people by being easy to use and to do things for you as a helpful elf/fairy would. [...] I remembered this when looking for research documents yesterday and spotting an old email about a drone meetup event called "Phantoms in the Forest" (see http://url.ie/12bze) (Notes on September, 2016)

The primary focus of my observations was slowly turned towards seeing and trying to understand what was going on in some of those not very articulate and sometimes surprising moves in how we (the group) and I (as the observer) talked about, understood or conceptualized the drone. This included many discussions with community members in the maker lab, often taking outset in popular culture references. Taking the drone home, I began fantasizing about the drone as an elf, a helpful spirit that lingers in the periphery of your attention, but when I met with the others, they had some slightly less poetic stories to tell. Maybe an elf with its own Snapchat channel? 
When talking about the drone and how we could re-think it in a positive way, one of the community members shared a Parks and Recreation clip of the character Ron having shot down a drone for delivering a gift to his house. The company behind the drone had looked up his address, and the character is known for highly valuing privacy. Thus the scene shows him knocking on the main character's door (Leslie Knope) in the rain at night, holding up a mangled drone that he has shot down [...] (https://www.youtube.com/watch?v=Uw60ZLZUIDc). On a funny note, well more so a strange note, before conveying that we wanted to showcase drones in a positive way the community member had mentioned attaching a knife to a drone to knock down icicles in the winter. (Notes on October, 2016)

It feels as if the drone is a magnet of words, thoughts, feelings, and ideas. At the same time as it is fun and evocative, it's also a nuisance, a pest, sneaky, dangerous, unreliable, almost invisible, an eye in the sky, something you'd wanna throw a rock at. Or not. The clip has Ron holding the mangled drone in his hands, like a wounded animal, like a piece of game, helpless and quite useless.

Our work is influenced by other products circulating in tech media [...], specifically Lily Robotics' Lily Drone (which turned out to be a scam) EHang's Ghostdrone as well as the extremely viral Snapbot by Snap (formerly Snapchat) which has just debuted in California. Lily and Snapbot both have anthropomorphic features including eyes and a mouth, and a description for Ghostdrone on TechCrunch's article states "Drone seeks companionship. Likes long walks in the mountains and the movie Airplane!" Furthermore, the founder of Lily Robotics refers to the Lily drone with the phrase "It flies itself," as a key selling point referring to a supposedly autonomous capability that does not really exist. (Notes on October, 2016).

Drones without a human operator? The buzz is there, it's all over the recommender engines when you're online. Drones are immensely practical and there are scores of business models and value propositions being pursued around the technology. But there was an emerging feeling in the community group that the drone had potential beyond the relatively low hanging fruits of other benign drone use: damage inspection, agricultural surveillance, aerial photography duties and so on. In our discussions, as we were toying around with it in the workshop and in my own private musings, our drone gradually became a thing that embodied many different future applications and purposes.

\subsection{The Naming}

We gave our drone a name. What is in a name? Well, quite a lot, it turns out. Naming the drone was a not a ceremony as such - it was indeed rather un-ceremonial. The group and I had discussed how (and if) we wanted to disrupt and distance the drone from being considered a tool or just another functional product with a neatly circumscribed and predictable business model, and giving the machine a name seemed a good starting point. In the spirit of our initial ethos of being explorative rather than closing the business case (whatever that meant), we toyed around with different ideas meant to contrast 
the recent tech naming conventions of personal assistants such as Alexa, Cortana, and Siri, all of which we perceived to be a bit high-tech or just about exactly what you'd call a robot. You can somehow feel what a person named Cortana would be like. The drone was eventually named Gilbert. Perhaps somewhat reminiscent of Dilbert, the cartoon character and perhaps a name that has a slightly old fashioned, cozy ring to it, a butler?

Before the project switched names due to voting, we were looking to create a logo for the project and were initially focusing on a logo involving Gilbert. Some examples of this included having a drone by some blocks representing a skyline with the text "Gilbert learns to fly." However, before this we had conducted a search online for sources of inspiration specifically around robots and mustaches. After talking about Lyft giving drivers pink mustaches for their cars, we joked about how Gilbert as a name somehow sounded like a person who would have a mustache. This led to me searching for images of robots with mustaches to use as points of inspiration for our own logo. (Notes on October, 2016).

Gilbert was shaping up, getting somewhere. A version of the drone had struck a chord. "Are you with Gilbert" became a way of asking other members or the community whether you were using the drone, and it seemed the name meant something to people - at least for some period of time. From meeting with different community members, word had gotten around that a few individuals were looking into re-thinking how Gilbert could become something.

We attributed positive character attributes to Gilbert. Gilbert was friendly, he was a member of the community, someone who could be helpful in some way. We had started creating an identity for Gilbert, and once Gilbert's personality became more concrete, we were less receptive to alternative applications for the drone that did not match his perceived character. (Notes on November, 2016).

One idea that emerged, based on a sense of Gilberts personality ("what would a Gilbert do?”), was for the drone to film locations to raise awareness of accessibility issues. After speaking online and meeting with the entrepreneur, he stated that there were several locations within the city that were dangerous for bicyclists. It emerged that Gilbert could perhaps be beneficial for civic engagement [25] by documenting dangerous areas and creating more tangible points of discussion with the public and local government. Gilbert would be a gentle public caretaker, a drone that was looking for opportunities and challenges in public spaces.

We began test filming with Gilbert, with the first run outside of the maker lab. This sparked new concerns and new challenges arose.

\subsection{The Sociomateriality of Flying}

The idea of drone is often kind of limited. What does it do other than fly. Or rather, it has this fantastic ability to actually fly. It's obviously not magic, but (just) a collection 
of wires, servos, propellers, protocols, algorithms, radio waves. It feels like it is challenging gravity, nimble, leaf-like in the wind. Maybe it will one day just fly along (silently), break the reins and connections to its human supervisors.

You learn a lot about drones by flying and doing test rounds with them. It's one thing to see the drone on a table, and another to touch it, fly it, and listen to it. It's noisy, feels a bit dangerous (until you get to know it a bit), and through flying it, a new sense of space emerges. Rather than merely looking at it in the maker lab, talking, brainstorming with a coffee and a laptop, flying Gilbert around included developing a new sensitivity to various weather conditions such as temperature, wind and humidity. You become gradually aware of the challenges of vertical and distance navigation, as well as obstacles in the form of buildings or other things that might obstruct line of sight or safety, both for people on the ground and for Gilbert. Flying outside highlights the materiality of the drone, as winter weather in Sweden quickly drains battery life. It also heightens the sense of the airspace being regulated in various ways and by various agencies. Of course, Gilbert cannot be flown near the airport, heavily trafficked public spaces and so on. But the announced yet still somewhat surprising presence of the Pope in our midsized Swedish city created a larger no-fly zone, practically grounding the drone for a period.

You develop a sense of a drone and the space it operates in, and concurrently you acquire a sense of the sociomaterial formation of the drone, the way conventions, ideas, discourse, rules, regulations, images, metaphors give shape to your sense of the airspace. Imagine: the drone cut loose from all this, free to roam around the city, free to go wherever it wants. Instead, what you typically get is a hash of concerns, of decisions and histories that govern the present, patrolling the airspace with regulations and all the 'social stuff', the infrastructural stuff. You can also feel it as a kind of inappropriateness; for example, if you are flying close to people you become very careful not to intimidate them, not to impart on them the kind of menacing presence that the drone can sometimes radiate.

We flew Gilbert in the fall, often when the ground was wet from after a rain, and thus we had to wipe any mud and debris from the landing gear. During these times we would notice light scratches on the landing gear, normal wear from use. The type of scratches you wouldn't normally pay attention to. But you could feel them when picking Gilbert up and putting him back into the carrying case. [There was] a growing sense of attachment for an important thing that we were becoming more associated with, there was a bit of unease. (Notes on November, 2016)

The drone also feels vulnerable, brittle somehow. Its rigid plastic casing and light weight is not something that inspires a lot of confidence in its ability to survive a fall from, say, 10 meters. Also, it's clearly not waterproof, not particularly aerodynamic, light and overall just a bit delicate. The wind carries it along when you fly, so you have to adjust continuously as you dodge obstacles. You run into a lot of situations where keeping the drone flying and in presentable shape is a bit of an effort. And so, we cared for Gilbert, for a while, taking care to keep the (his?) innards and surfaces in good shape. We didn’t want him to mess up or to be messed up. 


\section{$5 \quad$ Analysis and discussion}

In our case, the process of designing and 'making' was led along initially by a growing fascination of the drone as a malleable thing. When the drone entered the maker lab, a central figuration of the drone in the minds of the community leaned on the functional but also somewhat hostile assemblages of associations and figures described by [4]. The analysis shows how the process of re-figuration was not just a process of rethinking, but also included a feeling of the drone as 'lively', alive in its capacity to enchant.

Scene 1 begins with the researcher struggling to figure out what to do with the drone. Taking the drone home and discussing its cultural associations led to a new sense of the technology, and facilitated new, emergent figures of the drone. Could such feelings of a magic creature emerge in relation to a plastic consumer drone? Back in the maker lab, the reflections were used to critically assess the conventional understandings of the drone, and activities were gradually devoted to destabilize those. A figure of the drone as a benign, helpful, considerate and inherently non-threatening thing arose. A significant event here was the un-ceremonial naming of Gilbert. It was un-ceremonial, but also offered the drone a form of autonomy, bestowing upon it some power to shape or inspire the community, to collaborate, behave, inspire. The drone was animated and anthropomorphized. The drone was decorated (and re-decorated), moustaches were considered, phrases and other embellishments were used to address the network around the drone, making Gilbert into a lively thing. Torres et al. have suggested that there are a lot of possibilities to extend technological artefacts with "unique expressive personalities" that "go beyond neutral, atomic, functional, and obedient "things". A name can help in creating a felt intimacy with devices leading to better experiences through increased "pleasure, social inclusion, and personal value in devices" [26]. The act of changing the point of reference, from 'are you using the drone?' to 'are you with Gilbert?' acknowledges the Gilbert project and the drone's appropriateness for entering into new relationships. The name and associated character perhaps also provided a more articulated presence of the drone as a member of the maker lab community.

The naming and the figure created by the name seemed to carry on through in the process, working as a way of anchoring the question "what would Gilbert do?”. As Turkle puts it, things (or materials, assemblages) can be evocative objects rather than lifeless things. She suggests that "[w]e are on less familiar ground when we consider objects as companions to our emotional lives or as provocations to thought. The notion of evocative objects brings together these two less familiar ideas, underscoring the inseparability of thought and feeling in our relationship to things" [9: 5]. Evocative objects are also things that mean more than we can tell. They entail (somewhere in their constitution) something in excess of conventional meanings or essences. Such objects can feel subtly strange, unfinished or malleable. The researcher (the $2^{\text {nd }}$ author) started the engagement with the drone by associating 'spiritual' characteristics with it, suggesting that it could be magic and enchanted. When flying with it, it felt brittle and potentially dangerous, but also enchanted and slightly magical. 
Drawing on key ideas from the affective turn, political philosopher Jane Bennett [8] describes how things can be considered enchanted and how materials involve an element of vibrancy and vitality - things are, if we discard the strict separation of the organic and the inorganic so important to modernist scientific ontologies, vibrant with the possibilities of life, agency, and wonder. Bennett references Franz Kafka's story “The Cares of a Family Man”, in which the narrator reflects on the creature Odradek, a simple spool of thread that is (curiously) alive, and shows how Kafka cultivates a "state of wonder" in a disturbingly mundane depiction of a strange and enchanted object. The Gilbert project and the project of re-figuring the drone enrolled a similar form of enchantment and curiosity. The naming did not just bestow upon the drone some human-like form of personality. Perhaps it also oriented the researcher and the community towards an appreciation of the wonder of drones and the relatively unexplored potentials of seeing the drone as a more benign and caring agent.

To Bennett, cultivating a sense of enchantment is not just a kind of fanciful, magical thinking. It has consequences for political and moral reasoning and action, since it calls into doubt the modernist project of "disenchantment" and the ultimate knowability of an object, to focus on new possible connections, attachments and hybrids. Enchantment, a form of awe that is not a "fall on your knees" awe, part of an ethics of caring, a story that "suggests that you have to love life before you can care about anything" [7: 4]. Enchantment, writes Bennett, "involves, in the first instance, a surprising encounter, a meeting with something you did not expect and are not fully prepared to engage" [7: 5, emphasis added]. Discussing the DJI drone in the context of Chinese meanings and connotations, the project unfolded from the unexpected proposition that the drone could be a slightly magical creature, an elf, a helpful spirit or a fairy in the woods. The drone was not just an inert object waiting to be elaborated through a design process. As a thing, it was articulated within a dispersed mood amongst the community in the maker lab that emphasized the drone as animated, alive and ultimately "cared for": When Ron, in the video clip, shoots down the drone, we feel sorry for the little deformed metal creature, like a dead animal in his hand.

Gilbert was a challenge to fly. He was caught up and entangled within material, social, political/regulatory and even religious concerns. Being part of the team, Gilbert was subjected to many of the same kinds of legislations and structures - being grounded, being immobilized or locked away. Flying a drone, with all the complications, can better articulate the felt, embodied relations that we can have with enchanted objects, as well as the more readily recognizable categories we invoke when we talk about technologies as sociomaterially entangled with 'the social'. When flying, a drone is revealed as both threatening and fragile, menacing and a little unpredictable, but with a brittle, defenseless side too. It is noisy and perhaps nosy, it is cute but will cut your fingers or peep down your backyard if you're not careful. If it becomes too threatening, we can readily imagine the response: shoot it out of the sky with a shotgun! But the engagement with the drone gradually became a caring one, one of relishing in an interaction with Gilbert, keeping him safe from harm.

Is 're-figuration' (or indeed design) a fundamentally human-led activity? Design has a connotation of "intentional” shaping (the designer shapes an object, leads the pencil, 
cuts the material), but we suggest that there might be other, "more-than-human" energies at play in design. The engagement with the drone was at least in part driven along by the shared feeling of the drone as an enchanted object, a thing that is lively and agential. The emergent sense of the drone as somehow alive guided the process towards exploring new experiential trajectories for the drone as a felt object, making the typical associations with violence and intrusion less of a gut reaction.

Re-figuring through design includes furthering a kind of fuzzy undecidability and the probing (sometimes chaotic, fumbling) frame shifting, and allows such processes to be seen not as noise, but as an indication of possibilities. It involves an explorative process where the progression is searching, reflective, and reckless. Gilbert, for example, might at times embody a particular mood or aura. These were based on popular depictions or vague metaphors and ideas, but also on a rather incidental grounding due to a papal visit and a budding sense of care toward the brittle plastic gadget.

We find that design and critical exploration of (monstrous) technology can be usefully extended with affective and materialist perspectives suggested in this paper. Understanding how affective modulations, gut feelings and enchantments might shape the design process is also learning what affect does. Asking "what or how do things enchant me" or "how do I feel about this technology", widens the possibilities for re-figuration. We suggest that there are many opportunities for further research in the intersection of critical design practices and the process of re-figuring and re-enchanting technology. Bennett suggests that 'enchantment' as a quality of objects or technology goes against the dominant enlightenment discourses [7]. These would suggest that things are essentially inert and that only human actors are agential. To accept the affective shaping of a design process, the way feelings, senses, atmospheres or moods are entangled in processes and indeed 'thinking' and doing, might allow for different enchanted figures to emerge, figures that resist the dominance of functional properties or pragmatic application. In our case, Gilbert emerged from the growing sense of attachments and care. The moods, the felt attachments and care cultivated in the project created a sense of Gilbert as a companion or an enchanted object, and resisted military-, surveillance-, or similar applications.

Thus, what unites the opportunities that this paper suggests, is the increased orientation away from a 'modern constitution' [27] towards recognizing hybridity, connections, and crossings between the human and the non-human. In this paper, we have suggested more specifically on how feelings and affective engagements might be at play in a design project, suggesting that people can hold extensive relations with technology that go beyond the pragmatic and the identifiably purposeful. We see an opportunity to extend these studies in ways that are attentive to how objects become 'evocative' (or stirring, awe-some, or indeed enchanted) in practice, and what this might entail for a critical engagement with things in design. Being open to the wonder or enchantment of technologies, to let oneself be guided by vaguely felt atmospheric conditions or moods of a 'project' is a way to further destabilize dominant associations and affective states related to a technological figure. 


\section{Concluding remarks}

Our case involved joining and participating in a local maker space where we had access to a shared public artifact in the form of a drone. Through the case, we sought to reconceptualize the concept of drones by exploring alternative, and potential futures while engaged with the maker space community. Over the course of a few months, through interactions with community members and participating within the space in daily activities and special events, new understandings and crucially a new 'sense' of the drone emerged. Along these lines, our analysis of the emergence of various affective and felt work that allowed the drone to materialize as a vital, enchanted object. We suggest that concepts drawn from literatures affect, 'enchantment' and evocative objects and the assumption from most theories on sociomateriality that mind and matter is entangled, are useful for forming a fuller understanding of what living with technology can be.

Suggesting the possibility for what she calls a "vibrant matter" [8], we indicate that the body and the experiential are not merely 'containers' or environments for politics, values or figures of technology. Moral and ethical thought is, following Bennett, tied up with the ability to become enchanted by things in the world. Cultivating this form of enchantment is a road to more ethical and sustainable relations to things and to the world at large.

Crucially, following the ethos of critical design, cultivating affective and enchanted relations to technology may allow us to consider more broadly what human-technology relations can be like - they may lead us to futures that are less menacing and more attuned to favorable and "live-able" assemblages and entanglements of the human and the non-human. This is perhaps particularly required for creating new approaches and understandings of digital, ubiquitous, and interconnected technologies that come loaded with potentially quite literate monstrous, confrontational or forbidding connotations.

\section{References}

1. Shepardson, D. (2016). U.S. commercial drone use to expand tenfold by 2021: government agency. Reuters (2016), accessed May $14^{\text {th }}$, 2018. https://www.reuters.com/article/us-usadrones/u-s-commercial-drone-use-to-expand-tenfold-by-2021-government-agencyidUSKBN16S2NM

2. Manjikian, M. (2013). Becoming Unmanned. International Feminist Journal of Politics 16, no. 1 (01, 2013): 48-65. doi:10.1080/14616742.2012.746429.

3. Haggerty, K. D., \& Ericson, R. V. (2000). The surveillant assemblage. The British Journal of Sociology, 51(4), 605-622.

4. Andrejevic, M. (2016), Theorizing Drones and Droning Theory. In A. Završnik (ed.), Drones and Unmanned Aerial Systems. Springer International Publishing Switzerland 2016. DOI 10.1007/978-3-319-23760-2_2

5. Chang, V., Chundury, P., and Chetty, M. (2017). Spiders in the Sky: User Perceptions of Drones, Privacy, and Security. In Proceedings of the 2017 CHI Conference on Human Factors in Computing Systems (CHI '17). Boulder, Colorado, May 6-11. ACM, New York, NY, USA, 6765-6776. DOI: https://doi.org/10.1145/3025453.3025632

6. Clough, P. (2008). The affective turn: Political economy, bio-media and bodies. Theory, Culture \& Society 25(1): 1-22. 
7. Bennett, J. (2001). The Enchantment of Modern Life: Attachments, Crossings, and Ethics. Princeton, New Jersey: Princeton University Press.

8. Bennett, J. (2010). Vibrant Matter: A Political Ecology of Things. Durham, North Carolina: Duke University Press

9. Turkle, S. (ed.) (2007). Evocative Objects - Things we Think With. Cambridge, MA.; MIT University Press.

10. Hodder, I. (2012). Entangled: An Archaeology of the Relationships between Humans and Things. Malden, MA: Wiley-Blackwell.

11. Wetherell, M. Affect and discourse - What's the problem? From affect as excess to affective/discursive practice. Subjectivity (2013) 6: 349.

12. Bødker, M. \& Chamberlain, A. (2016). Affect theory and autoethnography in ordinary information systems. Twenty-Fourth European Conference on Information Systems (ECIS), Istanbul, Turkey, 2016.

13. McCarthy, J., \& Wright, P. (2004). Technology as Experience. Cambridge, MA. MIT Press.

14. Bødker, M. \& Jensen, T.B. (2017). Sounding out IS? Moods and affective entanglements in experiential computing. Twenty-Fifth European Conference on Information Systems (ECIS), Guimarães, Portugal, 2017

15. Kidd, A., \& Smitheram, J. (2014). Designing for affect through affective matter. Interstices, 15., 2014, http://interstices.aut.ac.nz/ijara/index.php/ijara/issue/view/1/showToc

16. Williams, R. (1977). Marxism and Literature. Oxford: Oxford University Press.

17. Böhme, G. (Translated by A.-Chr. Engels-Schwarzpaul) (2014). The theory of atmospheres and its applications, Interstices. 15. 2014. http://interstices.aut.ac.nz/ijara/index.php/ijara/article/view/201

18. Dunne, A. (1999). Hertzian tales: Electronic products, aesthetic experience and critical design. London: Royal College of Art.

19. Dunne, A. \& Raby, F. (2007). Critical Design FAQ. Retrieved May 12 2018. http://www.dunneandraby.co.uk/content/bydandr/13/0

20. Dunne, A. \& Raby, F. (2013). Speculative Everything - Design, Fiction, and Social Dreaming. Cambridge, MA. MIT Press.

21. Dunne, A. \& Raby, Fiona (2001). Design Noir: The Secret Life of Electronic Objects. Basel: Birkhäuser.

22. Bardzell, J \& Bardzell, S. (2013) What is “Critical” about Critical Design? CHI '13. Proceedings of the SIGCHI Conference on Human Factors in Computing Systems: 3297-3306

23. Pink, S., Akama, Y., \& Sumartojo, S. (2018). Uncertainty and Possibility: New Approaches to Future Making in Design Anthropology. London: Bloomsbury Publishing.

24. Orr, J. (1996). Images of work. Science, Technology, \& Human Values 23(4): 439-455.

25. Graeff, E., \& Matias, J.N. (2015). Making Drones Civic. Values and Design Principles for Civic Technology. International Studies Association's 56th Annual Convention, New Orleans, LA.

26. Torres, C., O'leary, J., and Paulos, E. (2016). LiveObjects. Leveraging theatricality for an expressive Internet of Things. Proceedings of the 2016, ACM Conference on Designing Interactive Systems - DIS '16 Companion, 2016. doi:10.1145/2908805.2908807.

27. Latour, B. (1993). We Have Never Been Modern (transl. Catherine Porter). Cambridge, MA.: Harvard University Press. 